\title{
A Novel Architecture of Maximum Power Point Tracking for Ultra-Low-Power Based Hybrid Energy Harvester in Ubiquitous Devices: A Review
}

\author{
${ }^{1,3}$ Michelle Lim Sern Mi, ${ }^{2}$ Sawal Hamid Muhammad Ali and ${ }^{1}$ Md. Shabiul Islam \\ ${ }^{1}$ Institute of Microengineering and Nanoelectronics (IMEN), \\ ${ }^{2}$ Department of Electrical, Electronic and System Engineering, \\ Faculty of Engineering and Built Environment, Universiti Kebangsaan Malaysia (UKM), 43600 Bangi, Selangor, Malaysia \\ ${ }^{3}$ Department of Microelectronics and Physics, Faculty of Applied Sciences and Computing (FASC), \\ Tunku Abdul Rahman University College (TAR UC), Jalan Genting Kelang, Setapak, 53300 Kuala Lumpur, Malaysia
}

Received 2013-07-07, Revised 2013-07-27; Accepted 2013-08-30

\begin{abstract}
This research work presents a novel architecture of an Ultra-Low-Power (ULP) based Hybrid Energy Harvester (HEH) consisting of multiple input sources such as kinetic, thermal and solar energy, harvested from passive human power. Having multiple ambient sources mitigates limitations caused by single sources especially for bodily-worn applications; however, this results in impedance mismatch among the different integrated sources. To overcome this limitation, the proposed ULP-HEH will use one power management unit with Maximum Power Point Tracking (MPPT) algorithm and impedance matching considerations to efficiently manage and combine power harvested from all three sources to achieve ULP consumptions. Among other crucial sub-modules of the ULP-HEH are its Asynchronous Finite State Machine (AFSM) cum resource sharing arbiter to prioritize and share energy sources for overall power reduction, an efficient rectification scheme for the piezoelectric input, an adaptive feedback for ULP conditioning, Zero-Current Switching (ZCS) for semi-lossless switching, a self-start circuit for low ambient startup, a Boost converter, a Buck regulator, a fuzzy-based micro-battery charger and a de-multiplexer to switch between harvesting or charging capabilities. All of which are implemented for maximum output extraction and minimal losses. This ULP-HEH will be developed in PSPICE software, Verilog coding under Mentor Graphics environment and later to be verified using Field Programmable Gate Array (FPGA) board before the final layout implementation in CMOS 0.13$\mu \mathrm{m}$ process technology. This battery-less ULP-HEH is expected to deliver $3.0-5.0 \mathrm{~V}$ of regulated voltage output from low ambient sources of $35 \mathrm{mV}$ at startup. An efficiency of $90 \%$ with an output power of $650 \mu \mathrm{m}$ is expected when all sources are summed. Also, this ULP-HEH is aimed at reducing power consumption to at least twice $(<70 \mu \mathrm{W})$ of conventional approaches. The proposed ULP-HEH can be used for ULP bodily-worn electrical gadgets, wearable biomedical devices or to charge micro-batteries for portable electronic devices.
\end{abstract}

Keywords: Hybrid Energy Harvester (HEH), Ultra Low Power (ULP), Maximum Power Point Tracking (MPPT), Resource Sharing Arbiter, FPGA

\section{INTRODUCTION}

Energy harvesting dates back to the days of windmills, waterwheel and waste heat when batteries and dynamos were yet to be invented by (Khaligh and Onar,
2009) respectively. The recent accelerated interest in renewable energy harvesting is primarily motivated by an exponential increase in energy consumption, an inevitable future exhaustion of fossil fuel as well as negative ecological effects (Michaelides, 2012). Today, and Built Environment, Universiti Kebangsaan Malaysia (UKM), 43600 Bangi, Selangor, Malaysia 
these renewable harvesting sources vary from solar, wind, thermal, ambient vibration, tidal wave, salinity gradient to the efficient reuse of exhaust heat discussed by (Yao et al., 2009). Acknowledging this need, various harvesting technologies, topologies and power electronics interfaces for stand-alone utilization or grid connection application has surfaced (Ramadass and Chandrakasan, 2009; Khaligh and Onar, 2009; Hamilton, 2012). Some of them preceded with mesoscale energy harvesting systems and later followed by CMOS process implementation (Ramadass and Chandrakasan, 2009) with popular application varying from Wireless Sensor Networks (WSN) to the recently sprouted human powered devices of pacemakers (Zervos, 2013), shoe inserts harvesters (Rocha et al., 2010) to a closed loop bio-medical monitoring system (Zhang et al., 2010) fuels interests in the human harvesting arena.

This literature focuses on the Ultra-Low-Power (ULP) based Hybrid-Energy-Harvester (HEH) human powered applications which began ever since the invention of self-winding watch by Abraham-Louise Perrelet in the year 1770 (Bonfiglio and Rossi, 2011). There are essentially three plausible types of energy sources for wearable devices, namely the mechanical acceleration, electromagnetic light energy and heat flow identified by Bonfiglio and Rossi (2011). Table 1 summarizes the energy harvesting opportunities and its demonstrated capabilities of these three energy sources (Vullers et al., 2009). For these three energy sources, there is a difference between unobtrusive energy and the effort driven micro-power generation such as a shaken torch light, in which case the latter is rejected altogether for Body Area Networks (BAN) in biomedical applications (Bonfiglio and Rossi, 2011).
The following paragraphs describe vibration-based energy harvesters with its interface circuits, followed by thermoelectric-based harvesters with its management circuitries and related CMOS process implementation, succeeded by a discussion on Maximum Power Point Tracking (MPPT) techniques with solar related literatures and finally ending with the hybrid architectures, implemented die micrographs, author's hypothesis and a conclusion to gauge micro-energy harvesters' potential in human powered applications.

Firstly, there are three main types of vibration-based generators, namely electrostatic, electromagnetic and piezoelectric (Kempitiya et al., 2012). These transducers became efficient with development of piezoelectric materials such as Lead Zirconate Titanate (PZT) and Polyvinylidene Fluoride (PVDF) (Rocha et al., 2010), multiple PZT structures (Zhu et al., 2011), encapsulated PZT nanofiber structure with $1.63 \mathrm{~V}$ of output voltage and $0.03 \mu \mathrm{W}$ of output power (Chen et al., 2010). Harvesting ambient vibration via PZT potentially supplies 10-100's $\mu \mathrm{W}$ of available power (Ramadass and Chandrakasan, 2009). Therefore, to complement these PZT structures, Rao and Arnold (2011) proposed an input-powered interface to solve the nonzero standby power consumption when no energy is harvested targeted at low amplitude output $(0.1 \mathrm{~V}-5 \mathrm{~V})$ and low frequency ac voltages of 1-500 Hz. Tabesh and Frechette (2010), designed an adaptive converter which optimally extracts power at $60 \%$ efficiency. Ramadass and Chandrakasan (2009), however reported 4-times improved power extraction via bias-flip rectification with lesser than $2 \mu \mathrm{W}$ of power consumption.

Table 1. Energy harvesting opportunities and demonstrated capabilities (Vullers et al., 2009)

\begin{tabular}{|c|c|c|}
\hline \multirow[b]{2}{*}{ Source } & \multicolumn{2}{|l|}{ Characteristics } \\
\hline & Source power & Harvester power \\
\hline \multicolumn{3}{|l|}{ Solar } \\
\hline Indoor & $0.1 \mathrm{~mW} / \mathrm{cm}^{2}$ & $10 \mu \mathrm{W} / \mathrm{cm}^{2}$ \\
\hline Outdoor & $100 \mathrm{~mW} / \mathrm{cm}^{2}$ & $10 \mathrm{~mW} / \mathrm{cm}^{2}$ \\
\hline \multicolumn{3}{|l|}{ Vibration } \\
\hline Human & 0.5m@1Hz1m/s@50Hz & $4 \mu \mathrm{W} / \mathrm{cm}^{2}$ \\
\hline Industrial & $1 \mathrm{~m} @ 5 \mathrm{~Hz} 10 \mathrm{~m} / \mathrm{s} @ 1 \mathrm{kHz}$ & $1100 \mu \mathrm{W} / \mathrm{cm}^{2}$ \\
\hline \multicolumn{3}{|l|}{ Thermal } \\
\hline Human & $20 \mathrm{~mW} / \mathrm{cm}^{2}$ & $30 \mu \mathrm{W} / \mathrm{cm}^{2}$ \\
\hline Industrial & $100 \mathrm{~mW} / \mathrm{cm}^{2}$ & $1-110 \mathrm{~mW} / \mathrm{cm}^{2}$ \\
\hline
\end{tabular}


On the other hand, D'hulst et al. (2010) suggests not to overlook converter's operating point by achieving $64 \%$ overall system efficiency while Aktata et al. (2011) uses rectifications with active diodes, shunt pass and a trickle charger to achieve power consumptions below $1 \mu \mathrm{W}$ with $50-60 \%$ efficiency compared to the architectures of Ramadass and Chandrakasan (2009) and Kwon and Rincon-Mora (2010) which requires initially charged batteries at $1.8 \mathrm{~V}$ and $2.5 \mathrm{~V}$ respectively.

Heat flow is another viable solution for lowpowered bodily worn gadgets, where both sides of the Thermo Electric Generators (TEG) is attached to body and chips will only have temperature differences of 1$2{ }^{\circ} \mathrm{C}$ thereby generating around $50 \mathrm{mV}$ (Kim and Kim, 2012). Recent thermal harvesters addresses this commonly low voltage issue of $25-50 \mathrm{mV}$ for bodyworn applications (Carlson et al., 2010; Ramadass and Chandrakasan, 2011; Im et al., 2012; Richelli et al., 2012). Carmo et al. (2010) fabricated a thermoelectric micro-converter based on thin films of bismuth and telluride to operate wireless electroencephalograms (EEG). Later, DC/DC Boosting techniques were used by Carlson et al. (2010), Ramadass and Chandrakasan (2011) and later by Richelli et al. (2012); Kim and Kim (2012) and Im et al. (2012) to increase efficiency of their power conditioning circuitries. Carlson et al. (2010) reported a control circuit that operates between 20 to 250 $\mathrm{mV}$ which produces a $1 \mathrm{~V}$ output from human body heat, consuming $1.6 \mu \mathrm{W}$ while delivering $25 \mu \mathrm{W}$. Ramadass and Chandrakasan (2011) also reported another interface circuit targeted at human body heat implemented on 0.35 $\mu \mathrm{m}$ CMOS process with a mechanical startup circuit at $58 \%$ efficiency which enables operation between $35 \mathrm{mV}$ to 1.8 Richelli et al. (2012) on the other hand fabricated an $0.18 \mu \mathrm{m}$ low-threshold CMOS process which incorporates an architecture for boosting $120 \mathrm{mV}$ to an output of $1.2 \mathrm{~V}$, delivering $220 \mu \mathrm{A}$ to the load and exhibiting $30 \%$ power efficiency.

To design interface circuits for improved power extraction, Kim and Kim (2012) and Im et al. (2012) proposed an incorporation of the MPPT algorithm popularly used in solar harvesting (Kim et al., 2011; Enne et al., 2012) for above $70 \%$ efficiencies at $0.5 \mathrm{~V}$ to $2.7 \mathrm{~V}$ of input voltages. The former literature (Kim and Kim, 2012) presents a DC/DC boost converter with variation-tolerant MPPT algorithm for dynamic frequency switching and a highly efficient Zero Current Crossing (ZCS) control circuit for wide conversion ratios implemented on a $0.35-\mu \mathrm{m}$ bipolarCMOS-DMOS (BCDMOS) process which outputs a 5.62 $\mathrm{V}$ from a $500 \mathrm{mV}$ supply at $\sim 72 \%$ efficiency. Im et al. (2012) also reported usages of MPPT control on 0.13- $\mu \mathrm{m}$ CMOS process chip capable of providing $2.7 \mathrm{~mW}$ from $40 \mathrm{mV}$ to $300 \mathrm{mV}$ supply with $61 \%$ efficiency at $2 \mathrm{~V}$ outputs where a transformer is self-started by thermal noise. This improved MPPT algorithm does not break the power transfer path and consumes less power (Im et al., 2012).

A hybrid system combines multiple harvesting technologies into a single system to overcome energy shortfalls of separate systems. These systems are an attractive solution to sufficient power delivery over a wide range of environmental conditions and devices (Hamilton, 2012). Colomer et al. (2011) has reported a multi-harvesting system that gathers and manages energy from multiple sources to deliver $\sim 6.4 \mathrm{~mW}$ of power on an Application Specific Integrated Circuit (ASIC) where each power source uses individual power management. Tan and Panda (2011), however reported a hybrid harvesting scheme that uses only one power management circuit alike Karthik et al. (2012) capable of $621 \mu \mathrm{W}$ of power generation, which triples single-source harvesting methods. Their chip was complemented by an efficient microcontroller based ULP management circuit, enhanced with MPPT with closed-loop voltage feedback control to ensure maximum power transfer (Tan and Panda, 2011). Another literature such as Karthik et al. (2012) also proposes one power management unit where the former reported $>80 \%$ charger efficiency (Karthik et al., 2012) at $330 \mathrm{mV}$ of kick-start voltage with clock gating and MPPT. Table 2 summarizes some of these past researchers' work on hybrid energy harvesters.

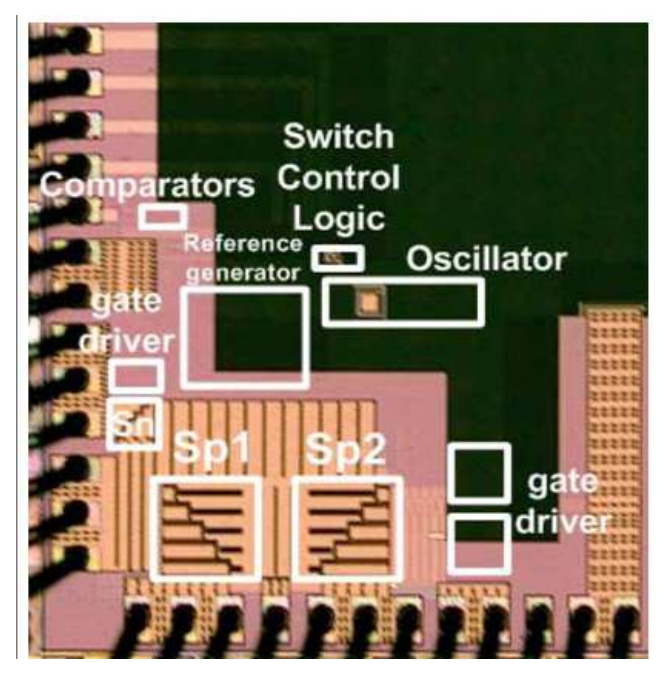

Fig. 1. Die micrograph of DIDO energy harvester for WBAN (Wang et al., 2011) 
Table 2. Past researcher works on hybrid energy harvesters

\begin{tabular}{|c|c|c|c|c|c|c|c|c|c|c|c|}
\hline \multirow[b]{2}{*}{$\begin{array}{l}\text { Researcher } \\
\text { (Year) }\end{array}$} & \multicolumn{11}{|l|}{ Parameters } \\
\hline & $\begin{array}{l}\text { Sources } \\
\text { (No.) }\end{array}$ & Architecture & MPPT & $\begin{array}{l}\text { Kick-start } \\
\text { scheme }\end{array}$ & $\mathrm{V}_{\mathrm{IN}}(\mathrm{V})$ & $\mathrm{V}_{\text {OUT }}(\mathrm{V})$ & $\mathrm{P}_{\mathrm{OUT}}$ & $\eta(\%)$ & $\begin{array}{l}\text { Power } \\
\text { Used (W) }\end{array}$ & $\begin{array}{l}\text { Process } \\
\text { Technology }\end{array}$ & $\begin{array}{l}\text { App. }^{\text {a }} \\
\text { (Is it dual } \\
\text { usage?) } \\
\end{array}$ \\
\hline $\begin{array}{l}\text { Tan and Panda } \\
\text { (2011) }\end{array}$ & $\begin{array}{l}\text { Light, Heat } \\
\text { (2) }\end{array}$ & $\begin{array}{l}\mathrm{DC} / \mathrm{DC} \\
\text { converter, } \\
\text { PWM gen., } \mathrm{MCU}\end{array}$ & Yes & None & $\sim 3.6$ & $\sim 5.5$ & $621 \mu \mathrm{W}$ & $\sim 90$ & $135 \mu \mathrm{W}$ & $\begin{array}{l}\mathrm{H} / \mathrm{W} \\
\text { prototype }\end{array}$ & $\begin{array}{l}\text { WSN } \\
\text { (No) }\end{array}$ \\
\hline $\begin{array}{l}\text { Colomer et al. } \\
\text { (2011) }\end{array}$ & $\begin{array}{l}\text { RF, PZT, } \\
\text { PV } \\
\text { (3) }\end{array}$ & $\begin{array}{l}\text { LDO regulator, } \\
\text { charge pump, } \\
\text { external SD }\end{array}$ & Yes & None & $\begin{array}{l}1(\mathrm{RF}), \\
1.2(\mathrm{PZT}), \\
1.89(\mathrm{PV})\end{array}$ & $1.2-2.5$ & $6.4 \mathrm{~mW}$ & $55-85$ & $160 \mu \mathrm{W}$ & $\begin{array}{l}\text { ASIC } \\
0.13 \mu \mathrm{m}\end{array}$ & $\begin{array}{l}\text { Low power } \\
\text { loads, } \\
\text { WSN } \\
\text { (No) }\end{array}$ \\
\hline $\begin{array}{l}\text { Wang et al. } \\
\text { (2011) }\end{array}$ & $\begin{array}{l}\text { PV, TEG } \\
\text { (2) }\end{array}$ & $\begin{array}{l}\text { Switch Control } \\
\text { Logic, Oscillator, } \\
\text { DIDO Boost } \\
\text { Converter }\end{array}$ & No & None & 0.5 & $0.9-1$ & $100 \mu \mathrm{W}$ & 55 & $0.23 \mu \mathrm{W}$ & $\begin{array}{l}\text { CMOS } \\
0.18 \mu \mathrm{m}\end{array}$ & $\begin{array}{l}\text { WBAN } \\
(\mathrm{No})\end{array}$ \\
\hline $\begin{array}{l}\text { Karthik et al. } \\
(2012)\end{array}$ & $\begin{array}{l}\text { PV, Heat } \\
\text { (2) }\end{array}$ & $\begin{array}{l}\text { Charger, FSM } \\
\text { and oscillator, } \\
\text { clock gating }\end{array}$ & Yes & $\begin{array}{l}\text { Cold start } \\
\text { (input } \\
\text { powered } \\
\text { Boost converter } \\
\text { (a) } 0.33 \mathrm{~V} \text { ) }\end{array}$ & 0.5 & 3 & Not stated & $>80$ & $\begin{array}{l}330 \mathrm{nA} \text { of } \\
\text { quiescent } \\
\text { current }\end{array}$ & $\begin{array}{l}\text { Fabricated } \\
\text { IC }\end{array}$ & $\begin{array}{l}\text { Battery and } \\
\text { supercap. } \\
\text { charger } \\
\text { (No) }\end{array}$ \\
\hline $\begin{array}{l}\text { Porcarelli et al. } \\
(2012)\end{array}$ & $\begin{array}{l}\text { Air-flow, } \\
\text { PV, Fuel } \\
\text { Cell (3) }\end{array}$ & $\begin{array}{l}\mathrm{DC} / \mathrm{DC} \text { in/ } \\
\text { output converter } \\
\text { charger, } \mathrm{MCU}\end{array}$ & Yes & None & $\sim 3$ & Not stated & $7 \sim 300 \mathrm{~mW}$ & $82-86$ & Not stated & $\begin{array}{l}\text { Meso-scale } \\
5 \times 6 \mathrm{~cm}^{2} \\
\text { PCB }\end{array}$ & $\begin{array}{l}\text { Li-ion } \\
\text { battery } \\
\text { charger } \\
\text { (No) }\end{array}$ \\
\hline $\begin{array}{l}\text { Bandyopadhyay } \\
\text { and } \\
\text { Chandrakasan } \\
(2012)\end{array}$ & $\begin{array}{l}\text { PZT, Heat, } \\
\text { PV(3) }\end{array}$ & $\begin{array}{l}\text { Dual Path } \\
\text { Approach, } \\
\text { inductor sharing }\end{array}$ & Yes & None & $\begin{array}{l}0.02-0.16 \\
\text { (Heat) } \\
0.15-0.75(\mathrm{PV}) \\
1.5-5(\mathrm{PZT})\end{array}$ & $1.88-2.3$ & $\begin{array}{l}1.3 \mathrm{~mW} \\
\text { (Heat) } \\
2.5 \mathrm{~mW}(\mathrm{PV}) \\
200 \mu \mathrm{W}(\mathrm{PZT})\end{array}$ & $\begin{array}{l}58 \% \text { (Heat) } \\
83 \% \text { (PV) } \\
79 \%(\mathrm{PZT})\end{array}$ & Not stated & $\begin{array}{l}\text { CMOS } \\
0.35 \mu \mathrm{m}\end{array}$ & $\begin{array}{l}\text { DSPs, } \\
\text { sensors } \\
\text { (No) }\end{array}$ \\
\hline $\begin{array}{l}\text { Sang et al. } \\
(2012)\end{array}$ & $\begin{array}{l}\text { EM, PZT } \\
\text { (2) }\end{array}$ & $\begin{array}{l}\text { Full bridge } \\
\text { rectifier }\end{array}$ & No & $\begin{array}{l}\text { Electro- } \\
\text { dynamic } \\
\text { Shaker }\end{array}$ & Not stated & 0.71 & $10.7 \mathrm{~mW}$ & $* 81.4 \%$ & $\begin{array}{l}\text { Not stated } \\
>\text { single } \\
\text { source EM }\end{array}$ & $\begin{array}{l}\text { Meso-scale } \\
\text { prototype }\end{array}$ & $\begin{array}{l}\text { WSN } \\
\text { (No) }\end{array}$ \\
\hline $\begin{array}{l}\text { Michelle et al. } \\
\text { (2013) }\end{array}$ & $\begin{array}{l}\text { PZT, Heat, } \\
\text { PV } \\
\text { (3) }\end{array}$ & $\begin{array}{l}\text { Resource sharing } \\
\text { Arbiter, AFSM, } \\
\text { ULP f/b, fuzzy } \\
\text { charger, DC/DC } \\
\text { converter, ZCS }\end{array}$ & Yes & $\begin{array}{l}\text { Self start } \\
\text { switch/ } \\
\text { power supply } \\
\text { manager } \\
\text { @ } \sim 35 \mathrm{mV}\end{array}$ & $0.1-0.3$ & $3.0-5.0$ & $>650 \mu \mathrm{W}$ & $>90$ & $<70 \mu \mathrm{W}$ & $\begin{array}{l}\text { CMOS } \\
0.13 \mu \mathrm{m}\end{array}$ & $\begin{array}{l}\text { Body worn } \\
\text { devices } \\
\text { cum } \\
\text { charger } \\
\text { (Yes) }\end{array}$ \\
\hline
\end{tabular}

a. Application.

As an example, three of the literatures Wang et al. (2011); Karthik et al. (2012) and Bandyopadhyay and Chandrakasan (2012) from Table 2 have fabricated and reported their die micrographs with Wang et al. (2011) die as shown in Fig. 1 bearing the closest resemblance to the proposed ULP based HEH because of its similar input sources and single power management unit. This literature focuses on DualInput Dual-Output (DIDO) Boost conversion for Wireless Body Area Network (WBAN) fabricated on a 0.18- $\mu \mathrm{m}$ CMOS process technology which occupies a die area of $1160 \times 1000 \mu \mathrm{m}$. The hybrid inputs are solar (M5525-0.5V) and heat (MPG-D651 TEG) with minimum input voltages of $0.5 \mathrm{~V}$ and very low power consumption of $0.23 \mu \mathrm{W}$ with $55 \%$ efficiency (Wang et al., 2011). The die of this DIDO harvester shows the placements of the adaptive frequency ring oscillator, gate driver, switch control logic, reference generator sub-blocks which constitute some main portion of its entire power conditioning architecture.
This literature survey shows profound interest in micro-energy harvesting for ULP devices. However, there is still a lack of low cost universal solution to battery or fossil power replacement as implementation of technology is application dependent, thereby one size does not suit all needs. Also, there is the concern of alternative energy efficiency, where in the case of a low cost crystalline silicon solar cell module, the efficiency barely reaches 20\% (Gassenbauer et al., 2013). This is where advanced circuit technology comes in by introducing almost lossless rectifications (Ramadass and Chandrakasan, 2009), power boosting circuitries by Carlson et al. (2010); Ramadass and Chandrakasan (2011); Richelli et al. (2012) and Kim and Kim (2012), timing controls (Kim and Kim, 2012), closed loop schemes (Zhang et al., 2010), MPPT algorithms (Im et al., 2012; Kim and Kim, 2012), as well as dual paths and inductor sharing schemes (Bandyopadhyay and Chandrakasan, 2012) in which the author has given a hypothesis on the contribution in this arena with the proposed ULP based HEH's specifications as summarized in Table 2 previously. 


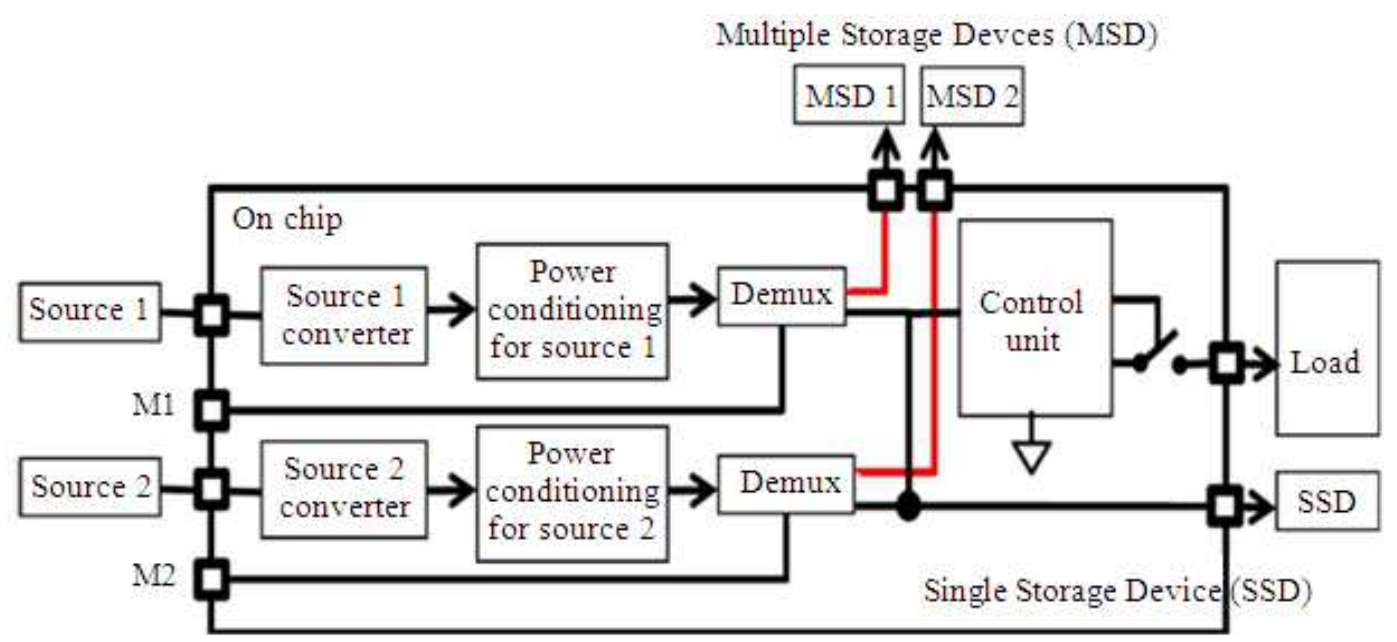

Fig. 2. Conventional architecture of HEH source with separate power management circuitries (Colomer et al., 2011)

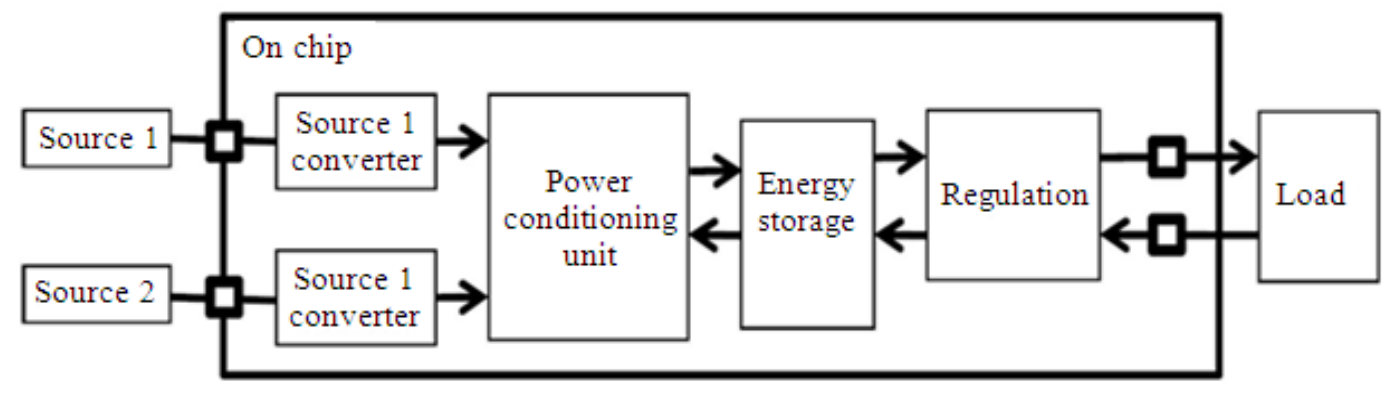

Fig. 3. Conventional architecture of HEH source with single power management circuitries (Tan and Panda, 2011; Sarpeshkar, 2010)

Therefore, the author proposes 3 input sources from solar, heat and vibration to be implemented on $0.13-\mu \mathrm{m}$ CMOS process technology with self-start mechanism, resource sharing capabilities, state machine, fuzzy-based charging, Buck and Boost converters with MPPTs. which is expected to obtain hypothetical output voltages of 3.0-5.0 $\mathrm{V}$ at more than $90 \%$ efficiency with below 70 $\mu \mathrm{W}$ of power consumption and a $\mathrm{V}_{\mathrm{IN}}$ of 100 to $300 \mathrm{mV}$ at an operating frequency of $4 \mathrm{kHz}$.

In a nutshell, to anticipate the energy crunching society that we are to become, energy harvesting technology and techniques has been rapidly advancing in the past few years. Significant efforts has been put forth to address limitations in the micro-scale energy harvesting arena. One substantial need is a robust, energy efficient harvester for ubiquitous devices, a hybrid harvesting device looks promising to overcome shortfalls of individual sources especially for delivering power to a much wider range of environment.

\subsection{Statement of Problem}

The purpose of this research is to address the problem faced by past researchers in most body-worn energy harvesters which suffers from low conversion ratios due to relatively low ambient input. Here, two conventional HEH topologies are given in Fig. 2 and 3. Figure 2 shows a conventional block diagram of an $\mathrm{HEH}$ with individual power conditioning circuitry for each individual source (Colomer et al., 2011). Sources can either be summed together or utilized separately (Colomer et al., 2011). This approach increases cost, form factor, power losses and requires external storage devices. Figure 3 represents another conventional HEH architecture with an improvement over Fig. 2. It shares a single power conditioning unit with built in energy storage such as the design proposed by Wang et al. (2011) and Tan and Panda (2011). The architecture in Fig. 3 improves the topology of Fig. 2 by form factor, cost and power losses as only one set of power management circuit is used. 


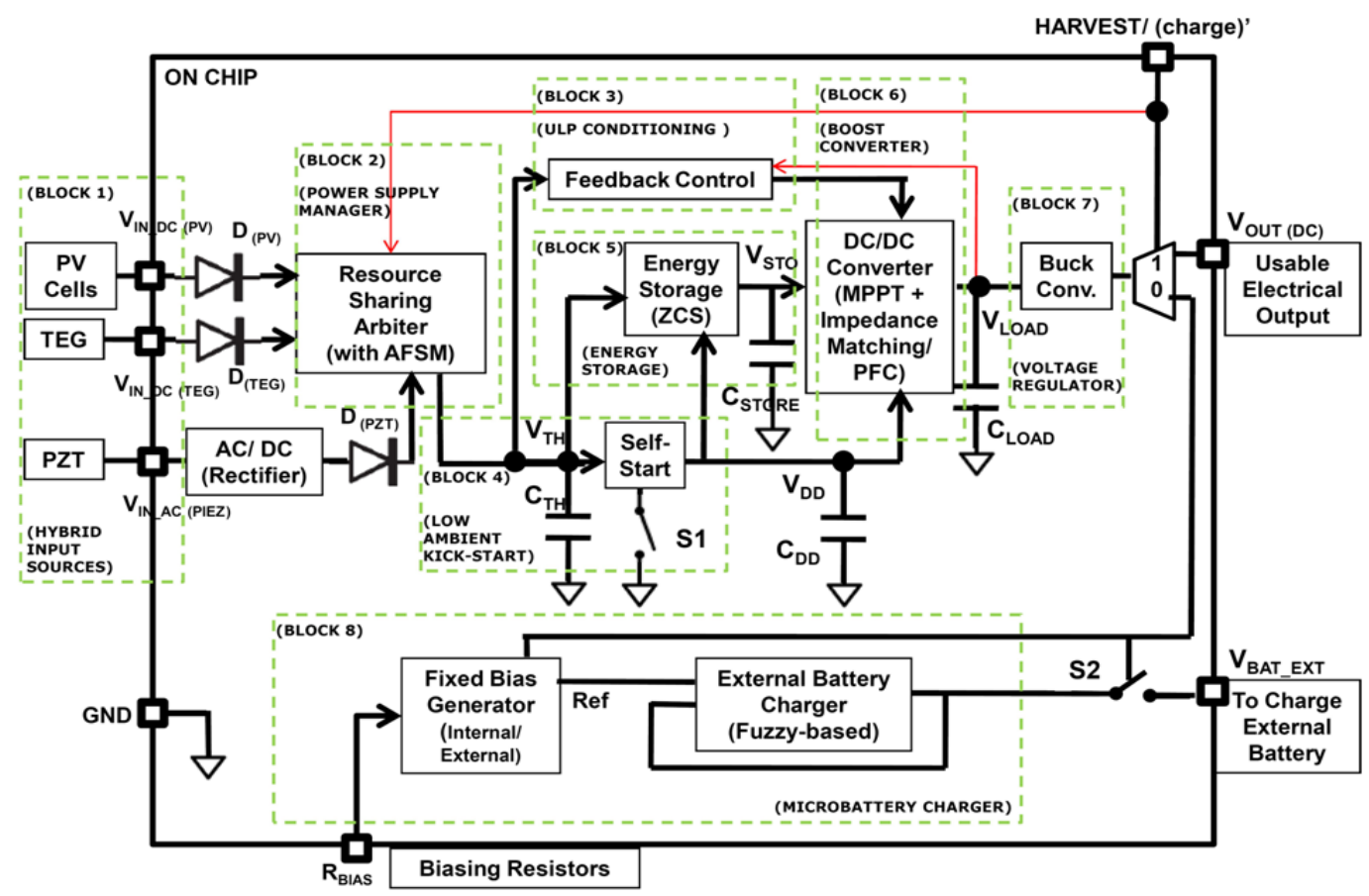

Fig. 4. Proposed architecture of the ULP based HEH for ubiquitous devices

However, the challenge is the possibility of impedance mismatching issue among the integrated energy sources (Tan and Panda, 2011).

The proposed solution to resolve the drawback of a single energy source is an HEH capable of converting sunlight, body heat and mechanical movement into electrical signals. Therefore, the proposed HEH system will have three input sources from the Photovoltaic (PV), TEG and PZT sources capable of combined or individual conditioning of harvested sources. On the other hand, this study also proposes a DC/DC converter which incorporates impedance matching and power factor correction considerations into its developed MPPT algorithm to address the multi-source impedance mismatch issue. Another challenge would be enabling the HEH system to consume as low power as possible; this is achieved with an adaptive low power conditioning feedback control loop, motivated by Rao and Arnold (2011). The proposed feedback loop will maintain the open circuit Voltage (Voc) of the HEH system by adjusting the duty cycle of the DC/DC Converter. It will also detect the absence of input energy and eliminate standby power consumption (Rao and Arnold, 2011).

Most HEH systems are either energy harvesters (Colomer et al., 2011; Tan and Panda, 2011) or external micro-battery chargers (Khosropour et al., 2012). This study propose to combine both the harvesting and charging ability of an HEH with possibly fuzzy logic implementation (Huang et al., 2009) which will potentially be integrated into the DC/DC buck charger of its harvester function to lower the overall form factor. The proposed ULP based HEH system uses no battery and in case of an ultra low ambient condition, has a selfstart circuit capable of kick-starting from a light human motion similar to that in (Ramadass and Chandrakasan, 2011). Above all, the proposed ULP based HEH architecture will be implemented on a $0.13-\mu \mathrm{m}$ CMOS process technology similar to the HEH conditioning interface circuit to extract maximum power found in Colomer et al. (2011). Finally, the purpose here is to investigate the best power conditioning interface circuit to extract maximum power and dissipate minimum losses.

\subsection{Description (Proposed Block)}

The proposed ULP based HEH architecture is shown in Fig. 4. It consists of eight sub-blocks i.e., (Block 1, Block 2,... Block 8) which represents the hybrid input sources, power supply manager, ULP conditioning circuitry, low-ambient kick-starter, energy storage, Boost converter with MPPT, Buck regulator and battery charger blocks respectively. All eight blocks will work together to address a few main challenging issues. These 
blocks will be subsequently explained by the following paragraphs here forth.

Firstly, the hybrid input sources such as PV, TEG and PZT (Block 1) are applied to the ULP based HEH. These sources represent the multi-ambient source for bodyworn devices applicable both outdoors under the sun and indoors with heat gradients or kinetic movement by the body to mitigate a possible absence of either one source. These sources are capable of powering up body worn devices to a multitude of voltage levels. The proposed ULP-HEH architecture captures solar power, human temperature gradient and vibration from the ambient environment via a PV Cell, TEG and PZT respectively. Only the PZT source which is a small signal alternating current requires efficient rectification from voltage doublers (Tabesh and Frechette, 2010), shunt pass switches (Aktata et al., 2011) to bias-flip chip methods (Ramadass and Chandrakasan, 2009) which achieves 4times better power extraction then conventional full bridge rectifiers. All three DC sources from the transducers are individually fed into diodes to avoid reverse current flow (Tan and Panda, 2011).

Secondly, these three hybrid input sources will then be fed into the power supply manager (Block 2) with resource sharing arbiter and an Asynchronous Finite State Machine (AFSM) to efficiently share resources and manage individual or summation of power supplies inspired by Ramadass and Chandrakasan (2009) and Colomer et al. (2011). The AFSM integrated into this block will decide between one of the four options which are: (i) to manage priority between the three sources when they are simultaneously present (Tan and Panda, 2011; Bandyopadhyay and Chandrakasan, 2012), (ii) to decide between harvesting external loads or charging an external battery based on the user selection feedback aided by a simple multiplexer. (iii) to activate "Request/Acknowledgement" signals between shared resources such as an inductor sharing request suggested by Ramadass and Chandrakasan (2009) or a possibility of bidirectional DC/DC conversion of "reverse-buck forward-boost" approach suggested by Arfin and Sarpeshkar (2012) in their energy efficient electrode stimulator, (iv) to trigger self-starting or energy recycling such as the inductor-based scheme to recycle energy between positive and negative phases reported by Kim and Kim (2012); Tan and Panda (2011) as well as Arfin and Sarpeshkar (2012).

Thirdly, the ULP feedback conditioning control (Block 3) is used to adaptively adjust duty cycle of $\mathrm{DC} / \mathrm{DC}$ converter based on feedback to ensure that $\mathrm{V}_{\text {OUT }}$ is stable and reduce power losses to its minimum motivated by Rao and Arnold (2011). It ensures ULP is consumed throughout the entire harvesting process. It maintains a stable open circuit voltage, $\mathrm{V}_{\mathrm{OC}}$ as well as adjusts duty cycle of the DC/DC Boost converter based on the driven load similar to the analog controller introduced by Tabesh and Frechette (2010). It also eliminates standby power consumption by automatically shutting down the ULP based HEH when the ambient inputs are too low for successful harvesting such as the input-powered AC/DC converter suggested by Rao and Arnold (2011).

Next, the low ambient kick-start block (Block 4) houses switch S1 acts much like the one by Ramadass and Chandrakasan (2011) which is included as a fail-safe block to ensure that an internal storage element starts charging once one or more ambient sources is detected and also to eliminate battery-startup dependencies such as those reported by Aktata et al. (2011). The self-start mechanism charges $C_{D D}$ to a minimal voltage value which will then trigger an internal clock within the selfstart block which then triggers CMOS switches to help pump in further charge into $\mathrm{C}_{\mathrm{DD}}$ to a proposed $2 \mathrm{~V}$ or above such as the one reported by Ramadass and Chandrakasan (2011).

Once the $\mathrm{V}_{\mathrm{DD}}$ reaches this voltage level, the energy storage block (Block 5) with ZCS for semi-lossless switching (Kim and Kim, 2012) is activated and energy is stored in a storage capacitor, $\mathrm{C}_{\mathrm{STORE}}$ which is designed to be much larger than $\mathrm{C}_{\mathrm{DD}}$ (Ramadass and Chandrakasan, 2009; 2011; Aktata et al., 2011). $\mathrm{C}_{\text {STORE }}$ will act as a buffer for this HEH system to ensure non-intermittent power supply and it can be used later on when no ambient sources are detected. Both $\mathrm{V}_{\mathrm{DD}}$ and $\mathrm{V}_{\text {STORE }}$ cannot be used to directly power loads as $\mathrm{C}_{\mathrm{DD}}$ will be designed to be small to maximize the net low voltage startup value after consideration of losses (Ramadass and Chandrakasan, 2011). Although the power is diverted into a much larger $\mathrm{C}_{\mathrm{STORE}}$ after a proposed $2 \mathrm{~V}$ value has been reached, $V_{\text {STORE }}$ is unstable and dependent on ambient input power available as well as the power consumed by the load (Tabesh and Frechette, 2010; Ramadass and Chandrakasan, 2011; Kim and Kim, 2012; Tan and Panda, 2011).

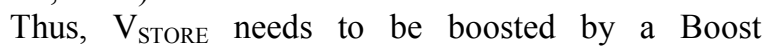
converter block (Block 6) where a developed MPPT algorithm (Im et al., 2012; Kim and Kim, 2012) is used to enhance power extraction while impedance matching is also incorporated to counteract the possibility of impedance mismatch caused by multiple power sources. Once boosted, the buck converter (Block 7) will regulate the $\mathrm{V}_{\text {STORE }}$ to a constant voltage value to power load circuits. Here, the MPPT, impedance matching and Power Factor Correction (PFC) is incorporated into the buck and boost converters to improve the ULP-HEH system's efficiency as well as impedance mismatches. 
Michelle Lim Sern Mi et al. / American Journal of Applied Sciences 10 (10): 1240-1251, 2013

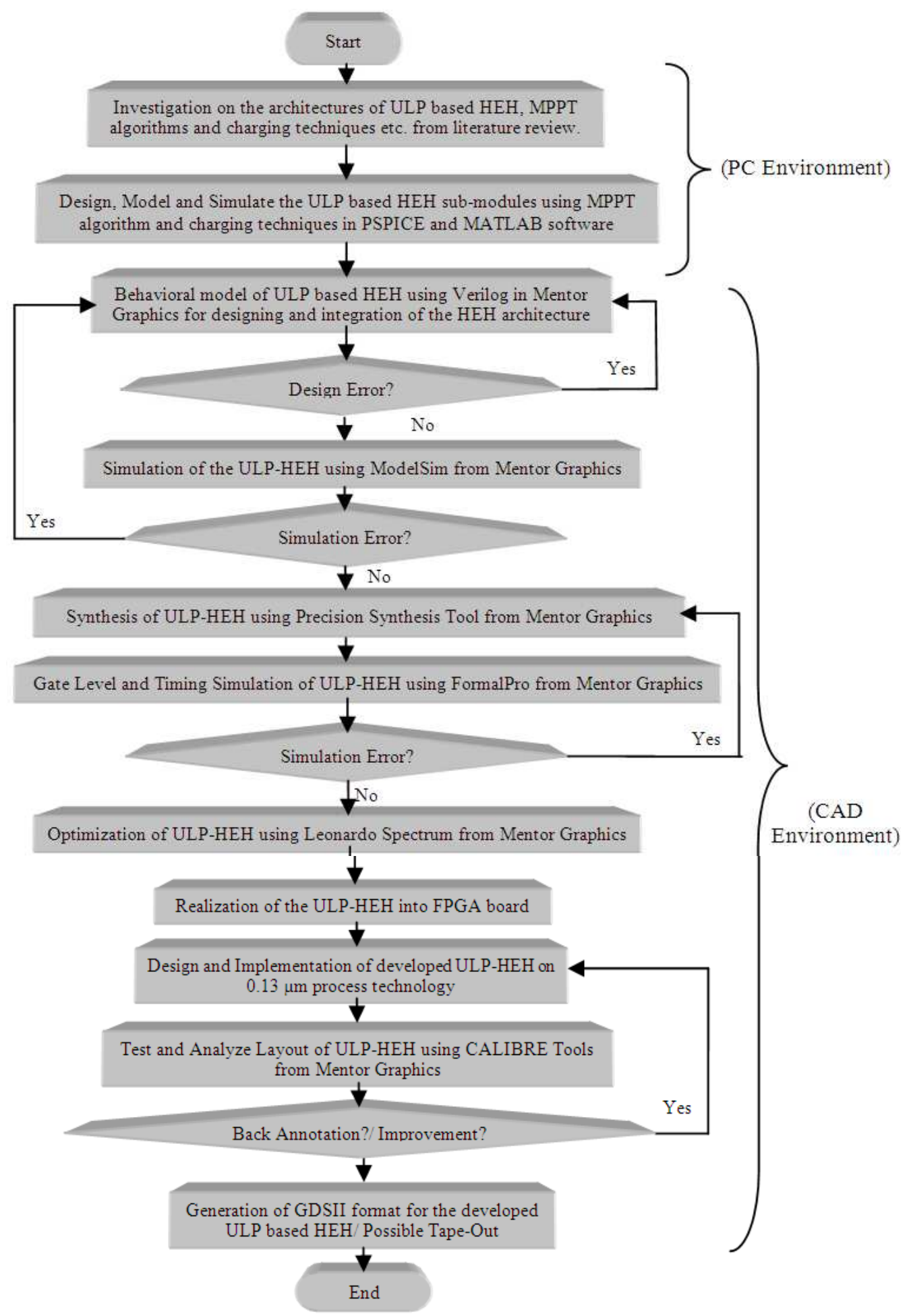

Fig. 5. Design flow chart of ULP based HEH architecture in PC and CAD environments 
Finally, this ULP-HEH has a micro-battery charger (Block 8) with the ability to provide Li-ion battery charging on top of operating as a power source harvesting for bodily worn devices. Externally through a de-multiplexer, if the charging of external batteries were activated via the HARVEST/(charge)' terminal, external Lithium ion batteries can be charged with either an internal biasing circuit inspired by Khosropour et al. (2012) and Valle et al. (2011) or an externally configured bias much like the solar/thermal charger proposed in Karthik et al. (2012) instead of functioning as a harvester. The proposed battery charger has its own fuzzy based feedback control to monitor external battery charging status similar to those reported by Carlson et al. (2010) and Valle et al. (2011). Therefore, with these eight subblocks efficiently integrated, the novel ULP based HEH architecture, implemented in $0.13-\mu \mathrm{m}$ CMOS technology, with 100-300 $\mathrm{mV}$ of input voltages from three ambient energy harvesting sources will be expected to deliver up to 3.0-5.0 V of output voltage which will be higher than past researchers of similar implementation platform, an efficiency above $90 \%$ and above $650 \mu \mathrm{W}$ of output power with merely $35 \mathrm{mV}$ of low kick-start value and below 70 $\mu \mathrm{W}$ of power consumption as well as the additional ability to charge external Li-ion batteries up to $3.0-5.0 \mathrm{~V}$.

\subsection{Implementation Process of HEH Architecture (Method)}

The design flow chart for the proposed ULP based $\mathrm{HEH}$ is as shown in Fig. 5 where it will start with an exhaustive literature review and end with the generation of tape-out ready GDSII format. This implementation process will be sequentially discussed using the following sub-blocks.

The process flow for this ULP based $\mathrm{HEH}$ is implemented in the $\mathrm{PC}$ environment and $\mathrm{CAD}$ environment. Firstly, in the $\mathrm{PC}$ environment, a review on the architectures of ULP based HEH architectures, MPPT algorithms and charging techniques. will be investigated. Next, each sub-modules of the ULP based HEH will be modeled, designed and simulated in the PSPICE software. On the other hand, MATLAB will be used for MPPT algorithms and fuzzy-based charging techniques. Here, the desired kick-start voltage as low as $\leq 35 \mathrm{mV}$ will be attempted. Any undesirable or erroneous simulation results especially regarding efficiency, power consumption, input and output voltages will be propagated back to the design or literature level. A successful simulation will lead to the design and integration of the ULP-HEH behavioral model written in
Verilog using Mentor Graphics which will be performed in the CAD environment together with all remaining tasks. This HDL based design of ULP-HEH will be simulated in the ModelSim and any discrepancies in design or simulation at this stage will lead back to the redesigning stage. Next, the behavioral model of ULP-HEH will be synthesized using the Precision Synthesis tool to enable a gate level simulation in the FormalPro tool. Any gate-level simulation faults will lead back to the synthesis stage.

An optimum gate-level synthesis will lead to the optimization of the gate-level ULP based HEH based on area, performance and power using the Leonardo Spectrum tool. If no further optimization is required, the optimized architecture will then be realized on the ULPHEH architecture and lead to the realization of ULPHEH by downloading into the Field Programmable Gate Array (FPGA) board as the target technology. With this successful FPGA implementation, the developed ULP$\mathrm{HEH}$ will then be designed and implemented as transistor level model on the $0.13 \mu \mathrm{m}$ process technology using Mentor Graphic's DA and IC station to obtain its final layout. Once the ULP-HEH layout is completed, testing and analysis will be conducted on the ULP-HEH layout and a series of tests will be done by CALIBRE to verify whether or not an improvement or back annotation is required before the final implementation especially if the ULP-HEH system has discrepancies in terms of parasitic, timing or power issues. After CALIBRE's verification on the ULP-HEH layout, the tape-out ready GDSII format can finally be generated to possibly be fabricated for real-life usages and validated for ubiquitous devices with human as ambient input sources.

\section{CONCLUSION}

A near optimal dual-functional ULP based $\mathrm{HEH}$ architecture has been proposed with both batterycharging and harvesting options. The main aim is to maximize the extracted input and minimize the power losses obtained from piezoelectric, photovoltaic and thermoelectric harvesters. This will be achieved by using an AFSM, a kick-start block, MPPT algorithm, impedance matching and feedback circuitry, ZCS as well as resource sharing approach to minimize losses throughout the ULP-HEH architecture. The proposed ULP-HEH architecture will be modeled, designed and simulated in PSPICE software, with MPPT and battery charging algorithm performed in MATLAB. The designed ULP-HEH will then realized on an FPGA and the layout verified in the $0.13-\mu \mathrm{m}$ CMOS process technology in Mentor Graphics environment. Finally, the 
expected result is to achieve a power reduction of at least 2-times $(<70 \mu \mathrm{W})$ conventional HEH with at least a 3.0$5.0 \mathrm{~V}$ regulated output at $4 \mathrm{kHz}$ operating frequency, $90 \%$ efficiency and a power of about $650 \mu \mathrm{W}$ when all three sources are simultaneously harvested which has the ability to constantly power or charge any low power wearable devices.

\section{REFERENCES}

Aktata, E.E., R.L. Peterson and K. Najafi, 2011. A selfsupplied inertial piezoelectric energy harvester with power-management IC. Proceedings of the International Solid-State Circuits Conference SolidState Circuits Conference Digest of Technical Papers (ISSCC), Feb. 20-24, IEEE Xplore Press, San Francisco, CA., pp: 120-121. DOI: 10.1109/ISSCC.2011.5746246

Arfin, S.K. and R. Sarpeshkar, 2012. An energyefficient, adiabatic electrode stimulator with inductive energy recycling and feedback current regulation. IEEE Trans. Biomed. Circ. Syst., 6: 113. DOI: 10.1109/TBCAS.2011.2166072

Bandyopadhyay, S. and A.P. Chandrakasan, 2012. Platform architecture for solar, thermal and vibration energy combining with MPPT and single inductor. IEEE J. Solid State Circ., 47: 2199-2215. DOI: 10.1109/JSSC.2012.2197239

Bonfiglio, A. and D. De Rossi, 2011. Wearable Monitoring Systems. In: Energy Harvesting for SelfPowered Wearable Devices, Leonov, V. (Ed.), Springer Science + Business Media, New York, USA., ISBN-10: 9781441973849, pp: 27-49.

Carlson, E.J., K. Strunz and B.P. Otis, 2010. A $20 \mathrm{mV}$ input boost converter with efficient digital control for thermoelectric energy harvesting. IEEE J. SolidState Circ., 45: 741-750. DOI: 10.1109/JSSC.2010.2042251

Carmo, J.P., L.M. Goncalves and J.H. Correia, 2010. Thermoelectric microconverter for energy harvesting systems. IEEE Trans. Ind. Electr., 57: 861-867. DOI: 10.1109/TIE.2009.2034686

Chen, X., S. Xu, N. Yao and Y. Shi, 2010. 1.6V nanogenerator for mechanical energy harvesting using PZT Nanofibers. Nano Lett., 10: 2133-2137. DOI: $10.1021 / \mathrm{nl} 100812 \mathrm{k}$

Colomer, F.J., P. Miribel-Catala, A. Saiz-Vela and 1. Samitier, 2011. A multiharvested self-powered system in a low-voltage low-power. Technology, 58: 4250-4263. DOI: 10.1109/TIE.2010.2095395
D'hulst, R., T. Sterken, R. Puers, G. Deconinck and 1. Driesen, 2010. Power processing circuits for piezoelectric vibration-based energy harvesters. IEEE Trans. Ind. Electr., 57: 4170-4177. DOI: 10.1109/PESC.2008.4592325

Enne, R., M. Nikolic and H. Zimmermann, 2012. A maximum power-point tracker without digital signal processing in $0.35 \mu \mathrm{m}$ CMOS for automotive applications. Proceedings of the International SolidState Circuits Conference Digest of Technical Papers (ISSCC), Feb. 19-23, IEEE Xplore Press, San Francisco, CA., pp: 102-104. DOI: 10.1109/ISSCC.2012.6176894

Gassenbauer, Y., K. Ramspeck, B. Bethmann, K. Dressler and J.D. Moschner et al., 2013. Rearsurface passivation technology for crystalline silicon solar cells: A versatile process for mass production. IEEE J. Photovoltaics, 3: 125-130. DOI: 10.1109/JPHOTOV.2012.2211338

Hamilton, M.C., 2012. Recent advances in energy harvesting technology and techniques. Proceedings of the 38th Annual Conference on IEEE Industrial Electronics Society, Oct. 25-28, IEEE Xplore Press, Montreal, QC, pp: 6297-6304. DOI: 10.1109/IECON.2012.6389019

Huang, C.H., C.C. Huang, T.C. Ou, K.H. Lu and C.M. Hong, 2009. Intelligent fuzzy logic controller for a solar charging system. Proceedings of the IEEE/ASME International Conference on Advanced Intelligent Mechatronics, Jul. 14-17, IEEE Xplore Press, Singapore, pp: 1412-1417. DOI: 10.1109/AIM.2009.5229853

Im, J.P., S.W. Wang, K.H. Lee, Y.J. Woo and Y.S. Yuk et al., 2012. A $40 \mathrm{mV}$ transformer-reuse self-startup boost converter with MPPT control for thermoelectric energy harvesting. Proceedings of the International Solid-State Circuits Conference Digest of Technical Papers (ISSCC), Feb. 19-23, IEEE Xplore Press, San Francisco, CA., pp: 104-106. DOI: 10.1109/ISSCC.2012.6176895

Karthik, K., Y. Ramadass, U. Lyles, J. Carpenter and V. Ivanov et al., 2012. A 330nA energy-harvesting charger with battery management for solar and thermoelectric energy harvesting. Proceedings of the International Solid-State Circuits Conference Digest of Technical Papers (ISSCC), Feb. 19-23, IEEE Xplore Press, San Francisco, CA., pp: 106-108. DOI: $10.1109 /$ ISSCC.2012.6176896

Kempitiya, A., D.A. Borca-Tasciuc and M.M. Hella, 2012. Analysis and optimization of asynchronously controlled electrostatic energy harvesters. IEEE Trans. Ind. Electron., 59: 456-463. DOI: 10.1109/TIE.2011.2141097 
Khaligh, A. and O.C. Onar, 2009. Energy Harvesting: Solar, Wind and Ocean Energy Conversion Systems. 1st Edn., CRC Press, Florida, ISBN-10: 1439815089, pp: 382.

Khosropour, N., F. Krummenacher and M. Kayal, 2012. Fully integrated ultra-low power management system for micro-power solar energy harvesting applications. Electr. Lett., 48: 338-339. DOI: 10.1049/el.2012.0315

Kim, J. and C. Kim, 2012. A DC-DC boost converter with variant-tolerant MPPT technique and efficient ZCS circuit for thermoelectric energy harvesting applications. IEEE Trans. Power Electr., 28: $3827-$ 3833. DOI: 10.1109/TPEL.2012.2231098

Kim, J., J.W. Kim and C. Kim, 2011. A regulated charge pump with a low-power integrated optimum power point tracking algorithm for indoor solar energy harvesting. IEEE Trans. Circ. Syst. Express Briefs, 58: 802-806. DOI: 10.1109/TCSII.2011.2173971

Kwon, D. and G.A. Rincon-Mora, 2010. A singleinductor AC-DC piezoelectric energyharvester/battery-charger IC converting $\pm(0.35$ to $1.2 \mathrm{~V})$ to $(2.7$ to $4.5 \mathrm{~V})$. Proceedings of the IEEE International Solid-State Circuits Conference Digest of Technical Papers (ISSCC), Feb. 7-11, IEEE Xplore Press, San Francisco, CA., pp: 494-495. DOI: $10.1109 /$ ISSCC.2010.5433867

Michaelides, E.E., 2012. Alternative Energy Sources. 1st Edn., Springer, New York, ISBN-10: 3642209513 , pp: 476.

Michelle, I.S., T. Yatsunenko, M.J. Manary, I. Trehan and R. Mkakosya et al., 2013. Gut microbiomes of malawian twin pairs discordant for kwashiorkor. Science, 339: 548-554. DOI: 10.1126/science. 1229000

Porcarelli, D., D. Brunelli, M. Magno and L. Benini, 2012. A Multi-Harvester architecture with hybrid storage devices and smart capabilities for low power systems. Proceedings of the IEEE International Symposium on Power Electronics, Electrcal Drives, Automation and Motion, Jun. 20-22, IEEE Xplore Press, Sorrento, pp: 946-951. DOI: 10.1109/SPEEDAM.2012.6264533

Ramadass, Y.K. and A.P. Chandrakasan, 2009. An efficient piezoelectric energy harvesting interface circuit using a bias-flip rectifier and shared inductor. IEEE J. Solid-State Circ., 45: 189-204. DOI: 10.1109/JSSC.2009.2034442

Ramadass, Y.K. and A.P. Chandrakasan, 2011. A batteryless thermoelectric energy harvesting interface circuit with $35 \mathrm{mV}$ startup voltage. IEEE J. Solid-State Circ., 46: 333-341. DOI: 10.1109/JSSC.2010.2074090
Rao, Y. and D.P. Arnold, 2011. An input-powered vibrational energy harvesting interface circuit with zero standby power. IEEE Trans. Power Electr., 26: 3524-3533. DOI: 10.1109/TPEL.2011.2162530

Richelli, A., S. Comensoli and Z.M. Kovacs-Vajna, 2012. A DC/DC boosting technique and power management for ultralow-voltage energy harvesting applications. IEEE Trans. Indus. Electr., 59: 27012708. DOI: 10.1109/TIE.2011.2167890

Rocha, J.G., L.M. Goncalves, P.F. Rocha, M.P. Silva and S. Lanceros-Mendez, 2010. Energy harvesting from piezoelectric materials fully integrated in footwear. IEEE Trans. Indus. Electr., 57: 813-819. DOI: 10.1109/TIE.2009.2028360

Sang, Y., X. Huang, H. Liu and P. Jin, 2012. A vibration-based hybrid energy harvester for wireless sensor systems. IEEE Trans. Mag., 48: 4495-4498. DOI: 10.1109/TMAG.2012.2201452

Sarpeshkar, R., 2010. Ultra Low Power Bioelectronics: Fundamentals, Biomedical Applications and BioInspired Systems. 1st Edn., Cambridge University Press, UK., ISBN-10: 978-0521857277, pp: 908.

Tabesh, A. and L.G. Frechette, 2010. A low-power stand-alone adaptive circuit for harvesting energy from a piezoelectric micropower generator. IEEE Trans. Indus. Electr., 57: 840-849. DOI: 10.1109/TIE.2009.2037648

Tan, Y.K. and S.K. Panda, 2011. Energy harvesting from hybrid indoor ambient light and thermal energy sources for enhanced performance of wireless sensor nodes. IEEE Trans. Indus. Electr., 58: 4424-4435. DOI: 10.1109/TIE.2010.2102321

Valle, B.D., C.T. Wentz and R. Sarpeshkar, 2011. An area and power-efficient analog li-ion battery charger circuit. IEEE Trans. Biomed. Circ. Syst., 5: 131-137. DOI: 10.1109/TBCAS.2011.2106125

Vullers, R.J.M., R.V. Schaijk, I. Doms, C.V. Hoof and R. Mertens, 2009. Micropower energy harvesting. Solid-State Electr., 53: 684-693. DOI: 10.1016/j.sse.2008.12.011

Wang, SW., J.P. Im and G.H. Cho, 2011. Dual-input dual-output energy harvesting DC-DC boost converter for wireless body area network. Proceedings of the IEEE Biomedical Circuits and Systems Conference (BioCAS), Nov. 10-12, IEEE Xplore Press, San Diego, CA., pp: 217-220. DOI: 10.1109/BioCAS.2011.6107766

Yao, D.J., K.J. Yeh, C.T. Hsu, B.M. Yu and J.S. Lee, 2009. Efficient reuse of waste energy. IEEE Nanotechnol. Mag., 3: 28-33. DOI: 10.1109/MNANO.2009.932420 
Zervos, H., 2013. 5 things you always wanted to know, thermoelectric energy harvesting. Energy Harvesting and Storage USA.

Zhang, X., H. Jiang, F. Li, S. Cheng, C. Zhang and Z. Wang, 2010. An energy-efficient soc for closed-loop medical monitoring and intervention. Proceedings of the IEEE Custom Integrated Circuits Conference (CICC), Sept. 19-22, IEEE Xplore Press, San Jose, CA., pp: 1-4. DOI: 10.1109/CICC.2010.5617381
Zhu, D., S. Beeby, 1. Tudor, N. White and N. Harris, 2011. Improving output power of piezoelectric energy harvesters using multilayer structures. Proc. Eng., 25: 199-202. DOI: 10.1016/j.proeng.2011.12.049 